near vision the patient fixes a near point and the distance between the corneal images of the light are taken as before.

The rule is obtainable from the manufacturers-Messrs. Theodore Hamblin, Ltd., Dispensing Opticians, 15, Wigmore Street, London, W.1.

\title{
A NEW CONJUNCTIVAL-FOLD FIXATION FORCEPS
}

\author{
BY \\ D. Stenhouse Stewart
}

HULL

Messrs. Down Brothers have made for me a pair of conjunctival-fold fixation forceps, each limb consisting of a curved foot fixed at an angle to the shank, the curvature of the foot being comparable to that of the sclera. At the heel and toe of this curved foot are $2 \times 1$ mouse teeth, the inner faces of the intermediate portion being slightly serrated.

In use, these forceps are applied to the eyeball with the jaws open, so that the teeth engage with a fold of conjunctiva of about

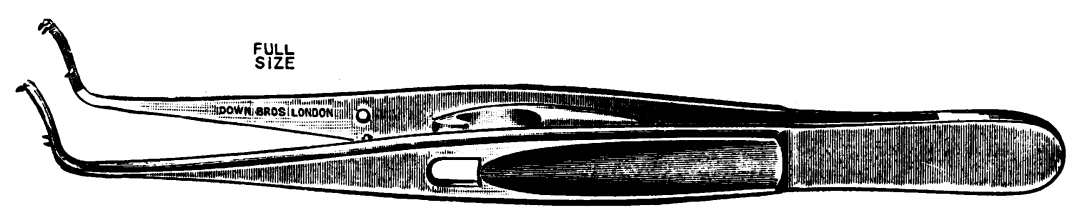

$8 \mathrm{mms}$. which rises between the jaws and is held there when the forceps closes. For convenience in handing to an assistant a spring catch is fitted.

The principal operation for which I use the forceps is that of iridencleisis, when a fold is taken as described, by fixing one limb at the upper corneal margin and drawing down the fold from conjunctiva which will ultimately cover the prolapsed iris. I introduce a Harrison Butler's knife through the conjunctiva, pass it beneath the forceps, the blades of which are as narrow as they can be, compatible with reasonable strength and rigidity, and enter it direct into the anterior chamber. The iris is drawn out, preferably with bottom toothed iris forceps with a curved foot of a similar type, after tearing its root by traction towards the pupil.

The drawn out portion can usually be released, and divided by de Wecker's scissors without transferring the fixation forceps to 
an assistant, but the spring catch allows this to be done if it is desired to retain a hold on the iris during its division. When the spring catch is released the fold of conjunctiva covers the wound spontaneously, and no further attention is required.

Carried out in this way, iridencleisis offers a much simpler substitute for the operation of sclero-corneal trephining, with considerably less trauma to the eye, and fully as satisfactory results. It is equally applicable to acute and chronic glaucoma and does not so suddenly reduce the tension. It is, in fact, necessary to

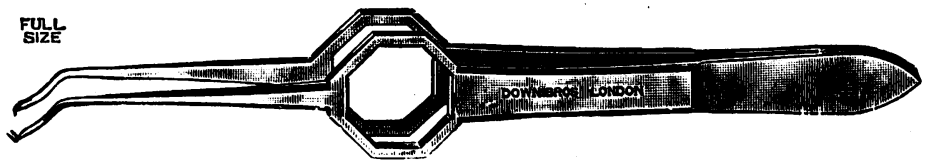

institute daily massage to the eyeball, commencing 24 hours after operation.

These forceps can be used for general fixation purposes with the advantage. that fold fixation gives better control of the eyeball. It gives one particularly a more secure hold if the conjunctiva is friable. It is also a satisfactory method of taking up a conjunctival flap or bridge for dissection to cover an ulcerated or damaged cornea.

I am greatly indebted to Messrs. Down Brothers for the trouble they have taken in carrying out repeated modifications of my original design, and in finally providing an instrument which I have found wholly satisfactory.

\section{OPHTHALMOLOGICAL SOCIETY OF THE UNITED KINGDOM ANNUAL CONGRESS, 1934}

THE Annual Congress of the Ophthalmological Society of the United Kingdom was held at the Royal Society of Medicine, London, on April 12, 13 and 14.

Mr. B. CRIDland, as Vice-President, was in the Chair in the absence of Mr. M. S. Mayou. Mr. Cridland expressed on behalf of the Congress sympathy for Mr. Mayou and his family in his illness, and regrets for his enforced absence and wished him a speedy recovery to good health. Miss Mann read Mr. Mayou's Presidential address on "The Surgical Treatment of the more 